\title{
Factor Analysis for Soil Test Data: A Methodological Approach in Environment Friendly Soil Fertility Management
}

Hari Dahal, Ph D²

\begin{abstract}
Soil test data were used in factor analysis employing the Principal Component Analysis technique for the reduction and summarization of soil variables. Principal component analysis was found to be highly suggestive in analyzing soil test data on which a rational fertilizer nutrients recommendation can be made for a sustainable soil fertility management reign.
\end{abstract}

\section{Introduction}

"No single resource is more important to achieving a sustainable agriculture than the soil which contains essential nutrients, stores the water for plant growth and provides the medium in which plants grow" (TAC/CGIAR, 1989).

The above statement shows in itself that soil resource management is the key to environmental friendly and sustainable agricultural system. Soil is natural resource that provides essential nutrients to crop growth, needs proper care, conservation and management in order to maintain a high degree of soil fertility systems. One of the ways to assess the soil fertility status is to get soil sample tested for different soil nutrient variables.

It is a common practice in soil testing that the test data are interpreted against a soil analysis rating chart (Annex 1). The chart gives ratings of values such as very low, low, medium, high and very high based on which recommendation of nutrients are made. Soil test data however as such have little to say about the rate at which fertilizer nutrients are recommended without calibrating into different soil fertility indices (Dahal, 1996). Besides, the rating itself can not give over all summarization of soil variables in terms of their individual contribution to soil fertility status in the enumeration units.

When a large number of variables are correlated redundancy of information due to the set of dependent variables may occur and in some cases even give rise to multicollinearity thus making the results difficult for interpretation. There is however technique in multivariate analysis in which variables are not classified as dependent or independent but the whole set of interdependent relationships are investigated. One of the most important techniques of interdependence relationship is factor analysis.

\section{Objective}

The purpose of this paper is to show how a number of soil variables could be reduced to a smaller number of dimensions by employing factor analysis so as to make an easier interpretation of the problems.

\section{Factor Analysis}

Factor analysis is a generic name denoting a family of statistical techniques primarily concerned with the reduction and summarization of observed variables in terms of common underlying dimensions or factors. The main objective of factor analysis is to obtain a way of condensing the information contained in a number of original variables into a smaller set of

\footnotetext{
2 Joint Secretary, Gender Equity and Environment Division, Ministry of Agriculture and Cooperatives, Singh Durbar, Kathmandu. Email: drdahal_h@yahoo.com
} 
variates (factor) with a minimum loss of information (Hair et al, 2003). Factor analysis that includes both principal component and common factor analyses is an extremely powerful analytical technique and can often indicate which variables in a set of data are important and which are having little significance.

\section{Principal Component Analysis (PCA)}

As is said earlier factor analysis includes both common factor analysis and principal component analysis and is functionally very similar in that they are used for the same purpose of data reduction but are quite different in their underlying assumptions. Principal component analysis assumes that the total variance of the observed variables should be used in the analysis while in common factor analysis (CFA) only the common variance is considered (Hair et al, 2003; George and Mallery, 2006). Unlike CFA, principal component analysis makes no assumption of a model; it is a mathematical linear transformation of the original variables, the objective of which is to account for the maximum share of the variability present in the original set of variables with a minimum number of composite variables known as principal components. Principal component analysis technique is far more common than common factor analysis particularly after the advent of high-speed computers. It is however to note that factors and components have been used interchangeably in factor analysis.

What technique to select is based mainly on the purpose of the analytical work? If it is just to reduce a large set of observed variables to a smaller set of uncorrelated variables then the use of PCA is appropriate. When the intention is to identify latent variables as to model some meaningful underlying constructs CFA is the suitable technique. For the purpose of this study principal component analysis as processed and analyzed in SPSS package will be illustrated here.

PCA is one of the multivariate methods of data analysis that transforms a number of correlated variables into smaller set of uncorrelated variables called principal components while maintaining most of the information in the original variables. Although a complex mathematical procedure, principal component can be expressed as:

$$
\begin{aligned}
& P C_{1}=a_{11} x_{1}+a_{12} x_{2}+\ldots .+a_{1 k} x_{k} \\
& P C_{2}=a_{21} x_{1}+a_{22} x_{2}+\ldots .+a_{2 k} x_{k} \\
& \ldots \ldots \ldots . . . \ldots \ldots \ldots . . . \\
& P C_{k}=a_{k 1} x_{1}+a_{k 2} x_{2}+\ldots .+a_{k k} x_{k}
\end{aligned}
$$

Subject to $a_{11}^{2}+a_{12}^{2}+\ldots .+a_{k k}^{2}=\operatorname{maximum}$.

Where, PCs are principal components, which are uncorrelated (orthogonal) with each other and also known as eigenvectors. The coefficients $a_{11}, a_{12}, a_{1 k}$ etc are assigned to the original $X s$ variables. The principal components are formed in decreasing order of importance which means the first principal component $\left(\mathrm{PC}_{1}\right)$ accounts for the maximum variance, $\mathrm{PC}_{2}$ has the next maximum variance and so on.

While performing the PCA if the variables are not all in the same units they should be standardized so that; 
$z_{j}=\frac{\left(x_{j}-\bar{x}_{j}\right)^{2}}{s_{j}}$, Where $z_{j}$ is the $z$-scores for the $\mathrm{j}^{\text {th }}$ variable, $\mathrm{x}_{\mathrm{j}}$ is the observed $\mathrm{j}^{\text {th }}$ variable and $\bar{x}_{j}$ is the mean of the $\mathrm{j}^{\text {th }}$ observed variables which is calculated as,

$\bar{x}_{j}=\frac{\sum_{i=1}^{n} x_{i j}}{n}$, Where $\mathrm{j}=1,2, \ldots . . \mathrm{k}$ and $n$ is sample and $\mathrm{s}_{\mathrm{j}}$ is the standard deviation of the $\mathrm{j}^{\text {th }}$ variate. The Pearson product moment formula is used for obtaining the correlation coefficients. If the correlation between 1 and 2 variables are worked out then;

$r_{12}=\frac{\sum_{i=1}^{N}\left(z_{i} 1 \times z_{i} 2\right)}{N}$

Where, $z_{i} 1$ and $z_{i} 2$ are the $z$ scores for sample $i$ on variables 1 and 2 .

$\mathrm{N}=$ sample size

\section{Methodology}

The soil test data for the principal component analysis were included from Kathmandu, Lalitpur and a Terai district of Banke for the fiscal year 2004-05. The samples were analyzed for organic matter $(\%)$, total nitrogen (\%), phosphorus $(\mathrm{kg} / \mathrm{ha})$, potassium $(\mathrm{kg} / \mathrm{ha})$ and $\mathrm{pH}$ (rating scale) in the soil laboratory, Soil Management Directorate of the Department of Agriculture, Nepal.

\section{Results and Discussions}

Analysis for Kathmandu soil variables from a total sample size of 50 was performed first to see the descriptive statistics and the whole factor analysis using PCA method in SPSS.10. The output is given in Table 1

Table 1 Factor Analysis Using Kathmandu Soil Test Data

Descriptive Statistics

\begin{tabular}{|l|r|r|r|r|r|}
\hline & $\mathrm{N}$ & \multicolumn{1}{|c|}{ Minimum } & Maximum & \multicolumn{1}{|c|}{ Mean } & Std. Deviation \\
\hline PH & 50 & 3.80 & 7.30 & 5.3220 & .8869 \\
OM & 50 & 1.10 & 8.07 & 3.4481 & 1.8612 \\
N & 50 & .05 & .40 & .1724 & $9.351 \mathrm{E}-02$ \\
P205 & 50 & 4.39 & 263.63 & 89.5166 & 69.8746 \\
K20 & 50 & 90.57 & 507.40 & 188.6806 & 97.3882 \\
Valid N (listwise) & 50 & & & & \\
\hline
\end{tabular}


Correlation Matrix a

\begin{tabular}{|c|c|c|c|c|c|c|}
\hline & & $\mathrm{PH}$ & OM & $\mathrm{N}$ & P205 & $\mathrm{K} 20$ \\
\hline \multirow[t]{5}{*}{ Correlation } & $\overline{\mathrm{PH}}$ & 1.000 & -.614 & -.616 & .181 & -.292 \\
\hline & OM & -.614 & 1.000 & 1.000 & -.144 & .403 \\
\hline & $\mathrm{N}$ & -.616 & 1.000 & 1.000 & -.140 & .399 \\
\hline & P205 & 181 & -.144 & -.140 & 1.000 & -.336 \\
\hline & K20 & -.292 & .403 & .399 & -.336 & 1.000 \\
\hline \multirow[t]{5}{*}{ Sig. (1-tailed) } & $\mathrm{PH}$ & & .000 & .000 & .104 & .020 \\
\hline & OM & .000 & & .000 & .159 & .002 \\
\hline & $\mathrm{N}$ & .000 & .000 & & 167 & .002 \\
\hline & P205 & .104 & .159 & .167 & & .009 \\
\hline & K20 & .020 & .002 & .002 & .009 & \\
\hline
\end{tabular}

a. Determinant $=3.862 \mathrm{E}-04$

KMO and Bartlett's Test

Kaiser-Meyer-Olkin Measure of Sampling

Adequacy.

Bartlett's Test of

Approx. Chi-Square

Sphericity

df

365.449

10

Sig.

.000

Communalities

\begin{tabular}{|l|l|r|}
\hline & Initial & Extraction \\
\hline $\mathrm{PH}$ & 1.000 & .607 \\
$\mathrm{OM}$ & 1.000 & .937 \\
$\mathrm{~N}$ & 1.000 & .938 \\
$\mathrm{P} 205$ & 1.000 & .810 \\
$\mathrm{~K} 20$ & 1.000 & .600 \\
\hline
\end{tabular}

Extraction Method: Principal Component Analysis.

Total Variance Explained

\begin{tabular}{|l|r|r|r|r|r|r|r|r|r|}
\hline & \multicolumn{3}{|c|}{ Initial Eigenvalues } & \multicolumn{3}{c|}{ action Sums of Squared Loaditation Sums of Squared Loadir } \\
\cline { 2 - 9 } Compon & \multicolumn{1}{|c|}{ Total } & \multicolumn{1}{|c|}{ of Varianqumulative } & Total & of Varianqumulative & Total & of Varianqumulative \\
\hline 1 & 2.811 & 56.216 & 56.216 & 2.811 & 56.216 & 56.216 & 2.556 & 51.130 & 51.130 \\
2 & 1.082 & 21.642 & 77.857 & 1.082 & 21.642 & 77.857 & 1.336 & 26.728 & 77.857 \\
3 & .634 & 12.689 & 90.547 & & & & & & \\
4 & .472 & 9.445 & 99.992 & & & & & & \\
5 & 38E-04 & $3.476 \mathrm{E}-03$ & 100.000 & & & & & & \\
\hline
\end{tabular}

Extraction Method: Principal Component Analysis. 


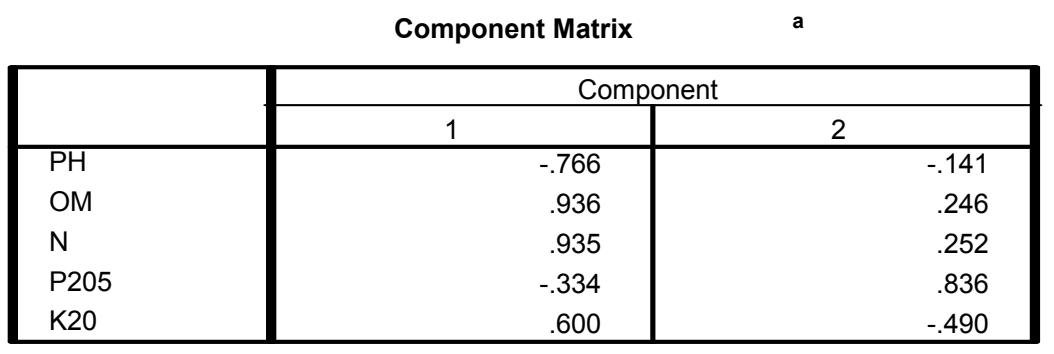

Extraction Method: Principal Component Analysis.

a. 2 components extracted.

Rotated Component Matrix a

\begin{tabular}{|l|r|r|}
\hline & \multicolumn{2}{|c|}{ Component } \\
\cline { 2 - 3 } & 1 & \multicolumn{2}{c|}{2} \\
\hline $\mathrm{PH}$ & -.762 & .164 \\
$\mathrm{OM}$ & .959 & -.132 \\
$\mathrm{~N}$ & .960 & -.126 \\
$\mathrm{P} 205$ & $1.164 \mathrm{E}-02$ & .900 \\
$\mathrm{~K} 20$ & .366 & -.683 \\
\hline
\end{tabular}

Extraction Method: Principal Component Analysis.

Rotation Method: Varimax with Kaiser Normalization.

a. Rotation converged in 3 iterations.

The descriptive statistics revealed the average values of soil attributes as acidic $\mathrm{pH}$, and a medium level of both organic matter and nitrogen. The phosphorus content of the soils was high with medium level of potash in the soils.

As to factor analysis, there is substantial number of variables correlated among each other. The Bartlett's Test of Sphericity that is a test statistic and used to test the null hypothesis that variables are uncorrelated to each other. This null hypothesis is rejected with the approximate chi-square value of 365.449 at 10 degrees of freedom. Kaiser-Meyer-Olkin, which is the measure of sampling adequacy (MSA), is found to be 0.666 suggesting the factor analysis an appropriate method to analyze the correlation matrix. KMO measure of sampling adequacy varies between 0 and 1 and the values closer to 1 are better whereas below 0.50 is unacceptable. The KMO value can be increased in many ways such as-increasing the sample size or increasing the number of variables. If the average correlations among the variables are high or the numbers of factor is diminished the value of KMO becomes large (Hair et al, 2003).

\section{Interpretation of Results}

Communalities as shown in Table 1 measure the amount of variance a variable shares with all the other variables in the analysis. This is also the proportion of each variable's variance explained by the principal components. It is also noted that the communality $\left(h^{2}\right)$ can be defined as the sum of squared factor (component) loadings. Large communality means a large amount of the variance in a variable is extracted by the factor solution. In other words, variables with high values are well represented in the common factor space while low value variables are not well represented (Malhotra N K, 2004). Communality can be calculated by squaring each component loading, adding and then multiplying by 100. 


$$
\begin{aligned}
& h^{2}=\left(p c_{1}\right)^{2}+\left(p c_{2}\right)^{2}+\ldots=\left(p c_{k}\right)^{2} \\
& \text { Where, } \begin{array}{l}
h^{2}=\text { communality } \\
p c=\text { principal component }
\end{array}
\end{aligned}
$$

\section{Initial Eigenvalues}

The eigenvalue is the variance explained by a component or factor and is denoted by lambda $(\lambda)$.

$$
\lambda_{k}=\sum_{i=1}^{n} A^{2}{ }_{i k}
$$

Where, $A_{i k}$ is the factor loading for variable $i$ on component $k$ and $n$ is the number of variables. A low eigenvalue contribute little to the explanation of variances in the set of variables being analyzed. The initial eigenvalues for the first and second components are 2.811 and 1.082 respectively (Table1). The percentage variance thus explained by each of the two components is about 56 and 22 with a cumulative percentage of 78 . In rotated sums of squared loading the eigenvalues have been more evenly distributed, 2.556 for the first component and 1.336 for the second leaving the total amount of variance the same. With the varimax rotation the interpretation of the component matrix has been simplified. The sum of the eigenvalues, as expected is equal to the number of variables being analyzed.

\section{Components Loadings}

The component matrix table shows the components loadings that are the correlations between the variables and the components. This is the central output of factor or principal component analysis, which is also the basis for imputing a label to the different factors of components (Nargunkar, 2005). It is the rule of thumb that larger the size of the component loading for a variable, the more important the variable is in interpreting the component. The first component is generally more highly correlated with the variables than the second components and so on. In interpreting, loadings above 0.6 are considered high where as those below 0.4 are low.

In the above example, the first table component matrix gives the unrotated solution and the second the rotated solution, which is the main basis for component interpretation. Looking at the rotated component matrix the first component has high loadings for three variables - $\mathrm{pH}$, organic matter, and nitrogen.

In second component, $\mathrm{P}_{2} \mathrm{O}_{5}$ is strongly associated and $\mathrm{K}_{2} \mathrm{O}$ is high but negatively correlated. Although there are many criteria to select components from the output analysis only two components were selected based on the Kaiser criterion. The Kaiser rule is to select those components or factors, which have eigenvalues greater than one (Gaur and Gaur, 2006).

\section{NAMING THE COMPONENTS}

In component 1 , nitrogen $(\mathrm{N})$ and organic matter $(\mathrm{OM})$ have very high loadings and both of which have positive signs. Thus nitrogen and organic matter vary together while pH having negative sign move in opposite direction. It means increased in soil pH is associated with the decreased in the availability of nitrogen and organic matter in soil systems. 
It is however to be noted that the optimum range of soil pH where most of the plant nutrients including nitrogen are available at the vicinity of 6.5 and 7.5 which is near to neutrality zone. Since soil pH is a reaction, a condition of nutrients availability the principal component 1 is represented by nitrogen and organic matter, which have very high loadings and are positively associated. The first component therefore can be named as "growth component" a factor responsible for vegetative growth and succulence in crops. The second component is primarily represented by $\mathrm{P}_{2} \mathrm{O}_{5}$ and in lesser extent by $\mathrm{K}_{2} \mathrm{O}$ that is negatively associated to the component. Both of these variables vary in opposite direction but have similar functions in crop production. The main responsibility of these variables includes vigor and resistance in the crops and can be named as "product quality component". It is therefore the components associated to soil fertility maintenance and crop growths in Kathmandu soils are identified as growth and product quality components out of five original variables involved in the principal component analysis.

LALITPUR DATA $(\mathrm{N}=46)$

The average soil reaction, organic matter, and nitrogen contents were similar to Kathmandu soils except that $\mathrm{P}_{2} \mathrm{O}_{5}$ and $\mathrm{K}_{2} \mathrm{O}$ contents were very high in the soils. Since the $\mathrm{KMO}$ measure of sampling adequacy was acceptable level $(0.588)$ and the Bartlett's test of sphericity was significant, the data were put into factor analysis. Two components were identified based on Kaiser criterion (Annex Table 2). The rotated component matrix shows all nutrient components except pH were associated with the first component explaining the variance of about 49 percent where as the second component shares about 21 percent. The first component may be named as "primary nutritional factor" and the second component as "soil reaction factor" together explaining the soil fertility variation by 70 percent.

Kathmandu Valley Data $(\mathrm{N}=105)$

Since the total amount of variance accounted for by the components in the above examples did not cross 80 percent it is thought the sample size in both cases to be inadequate. The data of both districts therefore were merged and adding nine more cases the sample size of 105 was made to represent the coterminous valley.

Table 2. Factor Analysis Using Valley Data

Descriptive Statistics

\begin{tabular}{|l|r|r|r|r|r|}
\hline & \multicolumn{1}{|c|}{ N } & \multicolumn{1}{|c|}{ Minimum } & Maximum & \multicolumn{1}{c|}{ Mean } & \multicolumn{1}{c|}{ Std. Deviation } \\
\hline PH & 105 & 3.00 & 8.20 & 5.3210 & .9447 \\
OM & 105 & 1.10 & 8.07 & 3.5932 & 1.6854 \\
N & 105 & .05 & .40 & .1798 & $8.456 \mathrm{E}-02$ \\
P205 & 105 & 1.32 & 1843.79 & 167.3671 & 259.5458 \\
K20 & 105 & 89.14 & 3857.63 & 470.9298 & 605.3024 \\
Valid N (listwise) & 105 & & & & \\
\hline
\end{tabular}


KMO and Bartlett's Test

\begin{tabular}{|c|c|c|}
\hline \multicolumn{2}{|c|}{$\begin{array}{l}\text { Kaiser-Meyer-Olkin Measure of Sampling } \\
\text { Adequacy. }\end{array}$} & 607 \\
\hline \multirow{3}{*}{$\begin{array}{l}\text { Bartlett's Test of } \\
\text { Sphericity }\end{array}$} & Approx. Chi-Square & 839.801 \\
\hline & $d f$ & 10 \\
\hline & Sig. & .000 \\
\hline
\end{tabular}

\begin{tabular}{|l|r|r|}
\multicolumn{3}{|c|}{ Communalities } \\
\hline \multicolumn{1}{|c|}{ Initial } & \multicolumn{2}{|c|}{ Extraction } \\
\hline PH & 1.000 & .660 \\
OM & 1.000 & .967 \\
N & 1.000 & .967 \\
P205 & 1.000 & .780 \\
K20 & 1.000 & .815 \\
\hline
\end{tabular}

Extraction Method: Principal Component Analysis.

Total Variance Explained

\begin{tabular}{|c|c|c|c|c|c|c|c|c|c|}
\hline \multirow[b]{2}{*}{ Component } & \multicolumn{3}{|c|}{ Initial Eigenvalues } & \multicolumn{3}{|c|}{ Extraction Sums of Squared Loadings } & \multicolumn{3}{|c|}{ Rotation Sums of Squared Loadings } \\
\hline & Total & $\%$ of Variance & Cumulative $\%$ & Total & $\%$ of Variance & Cumulative $\%$ & Total & $\%$ of Variance & Cumulative $\%$ \\
\hline 1 & 2.665 & 53.301 & 53.301 & 2.665 & 53.301 & 53.301 & 2.213 & 44.256 & 44.256 \\
\hline 2 & 1.525 & 30.500 & 83.801 & 1.525 & 30.500 & 83.801 & 1.977 & 39.545 & 83.801 \\
\hline 3 & .579 & 11.582 & 95.383 & & & & & & \\
\hline 4 & .230 & 4.608 & 99.991 & & & & & & \\
\hline 5 & $4.704 \mathrm{E}-04$ & $9.409 \mathrm{E}-03$ & 100.000 & & & & & & \\
\hline
\end{tabular}

Extraction Method: Principal Component Analysis.

Rotated Component Matrix

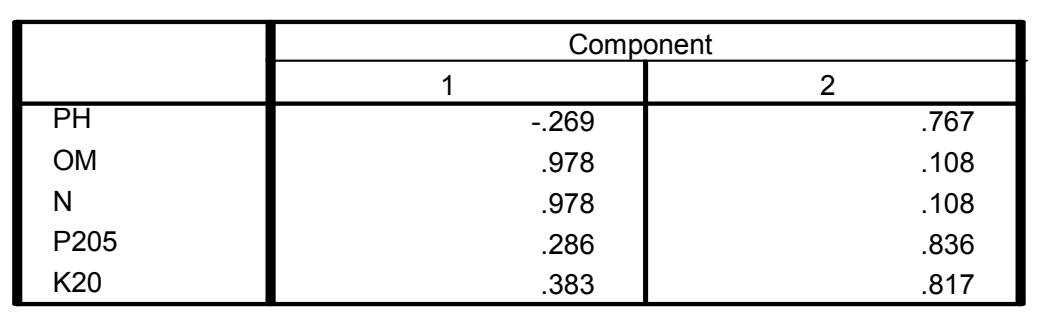

Extraction Method: Principal Component Analysis.

Rotation Method: Varimax with Kaiser Normalization.

a. Rotation converged in 3 iterations.

The descriptive statistics as shown in Table 2 revealed the soils as acidic, with a medium levels of organic matter and nitrogen content, very high level of $\mathrm{P}_{2} \mathrm{O}_{5}$ and high level of $\mathrm{K}_{2} \mathrm{O}$ per unit of area. Of the 10 correlations 8 were significant and KMO and Bartlett's test were in acceptable levels. With the application of latent root criterion two components were retained explaining a total of about $84 \%$ variance. The VARIMAX rotated components matrix revealed very high loadings of organic matter and nitrogen to the first component responsible for 44 percent of the total variance. The second component accounts for about 40 percent of the variance has high loadings of $\mathrm{P}_{2} \mathrm{O}_{5}, \mathrm{~K}_{2} \mathrm{O}$ and $\mathrm{pH}$. As of Kathmandu soils the first component may be called as "growth component" and second "product quality component" with a positive $\mathrm{pH}$ value. 
BANKE DATA $(\mathrm{N}=70)$

As of now the analysis was limited to Kathmandu valley soils, it was interesting to see if the analysis was markedly different for a low land Terai district of Banke. The measure of sampling adequacy (MSA) was miserably acceptable (0.524) with a significant Bartlett's test of sphericity. The descriptive statistics revealed acidic soils with low levels of both organic matter and nitrogen. The $\mathrm{P}_{2} \mathrm{O}_{5}$ content was very high while the $\mathrm{K}_{2} \mathrm{O}$ was medium.

Table 3 Showing the Factor Analysis Output for Banke Soil Data

Descriptive Statistics

\begin{tabular}{|l|r|r|r|r|r|}
\hline & $\mathrm{N}$ & \multicolumn{1}{|c|}{ Minimum } & \multicolumn{1}{c|}{ Maximum } & \multicolumn{1}{c|}{ Mean } & \multicolumn{1}{c|}{ Std. Deviation } \\
\hline PH & 70 & 4.80 & 7.50 & 5.5357 & .4553 \\
OM & 70 & .59 & 4.08 & 2.2103 & .6715 \\
$\mathrm{~N}$ & 70 & .03 & .20 & .1099 & $3.343 \mathrm{E}-02$ \\
P205 & 70 & 3.14 & 370.27 & 116.0833 & 78.1732 \\
K20 & 70 & 104.79 & 456.51 & 274.1207 & 81.4031 \\
Valid N (listwise) & 70 & & & & \\
\hline
\end{tabular}

\section{Factor Analysis}

Correlation Matrix a

\begin{tabular}{|c|c|c|c|c|c|c|}
\hline & & $\mathrm{PH}$ & OM & $\mathrm{N}$ & P205 & $\mathrm{K} 20$ \\
\hline \multirow[t]{5}{*}{ Correlation } & $\overline{\mathrm{PH}}$ & 1.000 & .060 & .051 & -.416 & -.173 \\
\hline & OM & .060 & 1.000 & .997 & .104 & .181 \\
\hline & $\mathrm{N}$ & .051 & .997 & 1.000 & .115 & .179 \\
\hline & P205 & -.416 & .104 & .115 & 1.000 & .396 \\
\hline & K20 & -.173 & .181 & .179 & .396 & 1.000 \\
\hline \multirow[t]{5}{*}{ Sig. (1-tailed) } & $\mathrm{PH}$ & & .311 & .338 & .000 & .076 \\
\hline & OM & .311 & & .000 & .195 & .067 \\
\hline & $\mathrm{N}$ & .338 & .000 & & .172 & .069 \\
\hline & P205 & .000 & .195 & .172 & & .000 \\
\hline & K20 & .076 & .067 & .069 & .000 & \\
\hline
\end{tabular}

a. Determinant $=3.833 \mathrm{E}-03$

KMO and Bartlett's Test

\begin{tabular}{|c|c|c|}
\hline \multicolumn{2}{|c|}{$\begin{array}{l}\text { Kaiser-Meyer-Olkin Measure of Sampling } \\
\text { Adequacy. }\end{array}$} & .524 \\
\hline \multirow{3}{*}{$\begin{array}{l}\text { Bartlett's Test of } \\
\text { Sphericity }\end{array}$} & Approx. Chi-Square & 370.006 \\
\hline & $d f$ & 10 \\
\hline & Sig. & .000 \\
\hline
\end{tabular}


Communalities

\begin{tabular}{|l|r|r|}
\hline & Initial & Extraction \\
\hline $\mathrm{PH}$ & 1.000 & .562 \\
$\mathrm{OM}$ & 1.000 & .984 \\
$\mathrm{~N}$ & 1.000 & .982 \\
$\mathrm{P} 205$ & 1.000 & .709 \\
$\mathrm{~K} 20$ & 1.000 & .476 \\
\hline
\end{tabular}

Extraction Method: Principal Component Analysis.

\begin{tabular}{|c|c|c|c|c|c|c|c|c|c|}
\hline \multirow[b]{2}{*}{ Component } & \multicolumn{3}{|c|}{ Initial Eigenvalues } & \multicolumn{3}{|c|}{ Extraction Sums of Squared Loadings } & \multicolumn{3}{|c|}{ Rotation Sums of Squared Loadings } \\
\hline & Total & $\%$ of Variance & Cumulative \% & Total & $\%$ of Variance & Cumulative \% & Total & $\%$ of Variance & Cumulative \% \\
\hline 1 & 2.123 & 42.463 & 42.463 & 2.123 & 42.463 & 42.463 & 2.047 & 40.934 & 40.934 \\
\hline 2 & 1.590 & 31.808 & 74.270 & 1.590 & 31.808 & 74.270 & 1.667 & 33.336 & 74.270 \\
\hline 3 & .780 & 15.592 & 89.863 & & & & & & \\
\hline 4 & .504 & 10.079 & 99.942 & & & & & & \\
\hline 5 & $2.889 \mathrm{E}-03$ & $5.779 \mathrm{E}-02$ & 100.000 & & & & & & \\
\hline
\end{tabular}

Extraction Method: Principal Component Analysis.

Rotated Component Matrix

a

\begin{tabular}{|c|c|c|}
\hline & \multicolumn{2}{|c|}{ Component } \\
\hline & 1 & 2 \\
\hline$\overline{\mathrm{PH}}$ & .167 & -.731 \\
\hline OM & .991 & 4.468E-02 \\
\hline $\mathrm{N}$ & .990 & 5.357E-02 \\
\hline P205 & 7.693E-02 & .838 \\
\hline $\mathrm{K} 20$ & .226 & .652 \\
\hline
\end{tabular}

Extraction Method: Principal Component Analysis.

Rotation Method: Varimax with Kaiser Normalization.

a. Rotation converged in 3 iterations.

Two components were extracted explaining about 74 percent variation (Table 3). Organic matter and nitrogen have very high loadings with the first component accounting for 41 percent of variance while 33 percent was accounted for second component in which $\mathrm{P}_{2} \mathrm{O}_{5}, \mathrm{~K}_{2} \mathrm{O}$ and $\mathrm{pH}$ have high loadings. As usual the first component may be termed as "growth component" because of its contribution in vegetative growth, chlorophyll and protein formation in the crops. The second component again may be called as "quality product component". The negative sign for $\mathrm{pH}$ in the second component indicates the reverse relationship between $\mathrm{pH}$ and other two variables. It is important to note that as the $\mathrm{pH}$ decreases the deficiency of $\mathrm{P}_{2} \mathrm{O}_{5}$ and $\mathrm{K}_{2} \mathrm{O}$ becomes pronounced.

\section{VALIDATING COMPONENT ANALYSIS}

Although PCA was highly meaningful in analyzing important soil variables in a set of test data the degree of generalizability is a critical issue. One of the important questions is to obtain suitable data in terms of number of variables and sample size. It has been observed that the sample size fewer than 50 is not suitable for analysis. In general a ten-to-one ratio between the number of observations and variable is said to be more appropriate. The analyses in the preceding paragraphs have also been constrained in the sense that the sample size for each of the districts was not sufficiently large. The number of variables were also limited to major nutrients only whereas adding cation exchange capacity (CEC), textural classes and micronutrients to the analysis could have given better results to interpret the components for soil fertility management. The generalization of these findings through the principal 
component analysis therefore should be done cautiously. Furthermore, the samples were tested as and when received and were not randomly selected to represent the population.

\section{Conclusions}

As expected principle component analysis has been shown to be a useful technique in reduction and summarization of soil variables. Among all five variables nitrogen $(\mathrm{N})$ was the most important soil nutrient followed by organic matter $(\mathrm{OM})$. Since nitrogen and organic matter are strongly associated number one component was highly loaded by these two variables in almost all cases. If organic matter is not considered as a nutrient, the second most important nutrient was Phosphorus. In most cases $\mathrm{P}_{2} \mathrm{O}_{5}$ and $\mathrm{K}_{2} \mathrm{O}$ with $\mathrm{pH}$ have high loadings with the second component. Although $\mathrm{K}_{2} \mathrm{O}$ is a third important nutrient, its loading in general was next to $\mathrm{pH}$. Its means in order to maintain soil fertility, balancing $\mathrm{pH}$ was more important than adding more of $\mathrm{K}_{2} \mathrm{O}$ fertilizer as its average levels was already medium to very high range in the soils.

\section{Acknowledgement}

The contribution in supplying soil test data for the purpose of this paper by the Chief and staffs of the Directorate of Soil Management, Department of Agriculture is gratefully acknowledged.

\section{REFERENCES}

1. Dahal, H: ECOLOGICAL APPROACH TO SUSTAINABLE AGRICULTURE THROUGH INTEGRATED NUTRIENT RESOURCE MANAGEMENT: A MICRO-LEVEL STUDY IN THE EASTERN TERAI FARMING SYSTEM, NEPAL. A Ph D Dissertation Submitted to the School of Environment, Resources and Development, Asian Institute of Technology (AIT), Bangkok, Thailand, April, 1996.

2. George D and P Mallery, 2006: SPSS for Windows- Step by Step. Pearson Education, Darling Kindersley (India).

3. Gaur A S and S S Gaur, 2006: Statistical Methods for Practice and Research. Response Books - A Division of SAGE Publication, New Delhi, India.

4. Hair J F, R E Anderson, R L Tatham and W C Black, 2003: Multivariate Data Analysis. Pearson Education, Singapore and India.

5. Malhotra N K, 2004: Marketing Research - an applied orientation. Pearson Education, Singapore and India.

6. Nargundkar R, 2005: Marketing Research-text and cases. Tata McGraw Hill Publishing Company Ltd, New Delhi, India.

7. TAC/CGIAR, 1989: Sustainable Agricultural Production: Implication for International Agricultural Research. Food and Agriculture Organization (FAO), Rome. 


\section{ANNEX}

Annex Table 1 Soil Analysis Rating Chart

\begin{tabular}{|l|l|l|l|l|}
\hline \multicolumn{1}{|c|}{ Rating } & Nitrogen \% & $\begin{array}{l}\text { Organic } \\
\text { Matter } \%\end{array}$ & $\begin{array}{l}\text { Phosphorus } \\
\mathrm{kg} / \mathrm{ha}\end{array}$ & Potassium kg/ha \\
\hline Very Low & \multicolumn{1}{c|}{$<1.0$} & $<10$ & $<55$ \\
\hline Low & $0.05-0.10$ & $1.0-2.5$ & $10-30$ & $55-110$ \\
\hline Medium & $0.10-0.20$ & $2.5-5.0$ & $30-55$ & $110-280$ \\
\hline High & $0.20-0.40$ & $5.0-10.0$ & $55-110$ & $280-500$ \\
\hline Very High & $>0.4$ & $>10.0$ & $>110$ & $>500$ \\
\hline
\end{tabular}

Source: Ministry of Agriculture and Cooperatives (Fertilizer Unit)/HMG/Nepal

Table 2 Factor Analysis Using Lalitpur Data

Descriptive Statistics

\begin{tabular}{|l|r|r|r|r|r|}
\hline & $\mathrm{N}$ & \multicolumn{1}{|c|}{ Minimum } & \multicolumn{1}{c|}{ Maximum } & \multicolumn{1}{c|}{ Mean } & \multicolumn{1}{c|}{ Std. Deviation } \\
\hline PH & 46 & 3.00 & 7.00 & 5.1022 & .7446 \\
OM & 46 & 1.33 & 6.39 & 3.4123 & 1.2567 \\
N & 46 & .07 & .32 & .1707 & $6.288 \mathrm{E}-02$ \\
P205 & 46 & 1.32 & 556.48 & 166.4380 & 140.1981 \\
K20 & 46 & 89.14 & 1987.76 & 589.7039 & 442.5319 \\
Valid N (listwise) & 46 & & & & \\
\hline
\end{tabular}

\section{Factor Analysis}

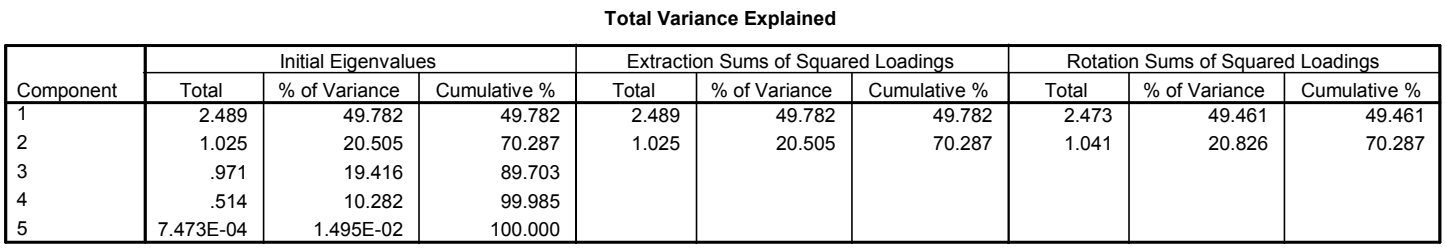

Extraction Method: Principal Component Analysis.

Rotated Component Matrix

a

\begin{tabular}{|l|r|r|}
\hline \multirow{2}{*}{} & \multicolumn{2}{|c|}{ Component } \\
\cline { 2 - 3 } & \multicolumn{1}{|c|}{2} \\
\hline PH & $5.306 \mathrm{E}-02$ & .974 \\
OM & .915 & $7.301 \mathrm{E}-02$ \\
N & .915 & $7.575 \mathrm{E}-02$ \\
P205 & .629 & -.228 \\
K20 & .631 & .171 \\
\hline
\end{tabular}

Extraction Method: Principal Component Analysis.

Rotation Method: Varimax with Kaiser Normalization.

a. Rotation converged in 3 iterations. 